\title{
Parametric Optimization Of Single Cylinder Diesel Engine For Palm Seed Oil \& Diesel Blend For Brake Thermal Efficiency Using Taguchi Method
}

\author{
Maulik A Modi ${ }^{1}$, Tushar M Patel ${ }^{2}$, Gaurav P Rathod ${ }^{3}$ \\ I (ME Scholar, Department of Mechanical Engineering , LDRP-ITR/ KSV University,India) \\ ${ }_{2}^{2}$ (Associate Professor, Department of Mechanical Engineering , LDRP-ITR/ KSV University,India) \\ ${ }_{3}^{3}$ (Assistant Professor, Department of Mechanical Engineering , LDRP-ITR/ KSV University,India)
}

\begin{abstract}
An experimental study has been carried out for palm seed oil blended with diesel used in a single cylinder diesel engine. Palm seed oil is obtained from the seeds of palm tree. In this study, the effects of parameters` i.e. load, compression ratio and injection pressure are taken as variable for optimization. As the experiment required simultaneously optimization of three parameters with three levels, Taguchi method of optimization is used in this experiment. The results of the Taguchi experiment identify that 16 compression ratio, injection pressure $180 \mathrm{bar}$ and engine load 10kg are optimum parameter setting for highest brake thermal efficiency. Engine performance is mostly influenced by engine load and is least influenced by compression ratio. Confirmation experiment was done using an optimum combination showed that the brake thermal efficiency was found by experiment is closer to the predicted value.
\end{abstract}

Keywords: - Parametric optimization, Diesel engine, Palm seed oil, Brake thermal efficiency, Taguchi method

\section{INTRODUCTION}

In today's era diesel engines are widely used for transport, industrial \& agricultural machinery due to its superior fuel efficiency. The increasing cost of petrol has made people to depend largely on diesel based engines. Due to depletion and higher cost of petroleum based fuels researchers around the world look for alternate fuel and trying to find out the best alternative fuel, which is used as a biodiesel

K. Sivaramakrishnan et.al show that there is much possibility of increase research in biodiesel, karanja biodiesel used as a biodiesel with taguchi multiple regression analysis and got better result for performance.[1] Anant Bhaskar Garg et.al used artificial neural network based methodologies for optimization of engine operations.[2] GVNSR Ratnakara Rao et.al done experiment and optimize the compression ratio for diesel engine and got better result for performance.[3] M. Natrajan et.al used variation risk analysis approach for optimizing diesel engine for low emission and got desired result for low emission.[4] N. Balajiganesh et.al used artificial network method for optimizing CI engine parameter.[5] Mr. Krunal B Patel et. Al showed in research paper that taguchi method of optimization is best technique for optimization and got better result for specific fuel consumption for predicted value $\&$ experimental value.[6]

In such multivariate problems, use of non linear techniques like Design of Experiments (DoE), fuzzy logic and neural network are suitable to explore the combined effects of input parameters. The optimum operating parameters for a given system can be determined using experimental techniques but experimental procedure will be time consuming and expensive when the number of parameters is more like 10, 20,etc., in the case of IC engines. In such situations mathematical modelling will be a very useful tool for optimizing the parameters. Such mathematical tool is Design of Experiment. Although few studies were reported using DoE in IC Engine applications, the study on combined effects between input system parameters such as injection pressure, load, compression ratio on the performance and emission characteristics of CI engine was scarce and offered a scope for this study.

\section{PALM SEED OIL}

The fuel properties like flash point, fire point, kinematic viscosity, density, calorific value. These fuel properties were compared with diesel fuel. Flash point and fire point were higher than diesel this confirmed the safety of biodiesel storage. Kinematic viscosity and density were higher than diesel this may result in improper spray characteristics. Cetane number was higher than diesel and it would have positive impact on combustion quality of biodiesel. 
Table-1.The fuel Properties of Palm seed oil and Diesel

\begin{tabular}{|c|c|c|c|c|}
\hline Fuel Property & ASTM & Palm Seed Oil & Diesel & Unit \\
\hline Density at $15^{\circ} \mathrm{C}$ & D4052 & 882 & 830 & $\mathrm{Kg} / \mathrm{m}^{3}$ \\
\hline $\begin{array}{c}\text { Kinematic Viscosity at } \\
40^{\circ} \mathrm{C}\end{array}$ & $\mathrm{D} 445$ & 7.01 & 3.05 & $\mathrm{cSt}$ \\
\hline Flash Point (PMCC) & D93 & 110 & 56 & ${ }^{0} \mathrm{C}$ \\
\hline Fire Point & D93 & 140 & 63 & ${ }^{0} \mathrm{C}$ \\
\hline Cetane Number & D613 & 77 & 51 & ---- \\
\hline Sulphated Ash & D874 & NIL & 0.001 & $\%$ by mass \\
\hline Gross Calorific Value & D4809 & 33360 & 42000 & $\mathrm{Kj} / \mathrm{kg}$ \\
\hline
\end{tabular}

\section{EXPERIMENTAL SET UP}

Experiments were conducted with Diesel and different volume proportions of palm seed oil as a Blend by $10 \%, 20 \%$ and $30 \%$ with Diesel. And take reading for different load condition. And do comparison between Diesel, B10, B20 and B30 blend. In this experiment, diesel engine is used and connected with the eddy current dynamometer with the help of dynamometer, varies the load on the engine or load remain constant .Gas analyzer is used to find the emission characteristic of exhaust gas. The reading takes by constant load or by varying the load on the engine using the dynamometer. Engine performance such as brake power, indicated power, brake thermal efficiency, brake specific fuel consumption etc. found from the experiments. First only diesel fuel is used and emission characteristics and engine performance is found .Then the blending of diesel and Palm seed oil at different proportion like 10\%, 20\%, and 30\% concentration is used to find the emission characteristics and engine performance of the engine. By taking the analysis of the various blend of diesel and palm seed oil to get the optimum value of blend for better quality of emission and performance characteristics of Diesel Engine.

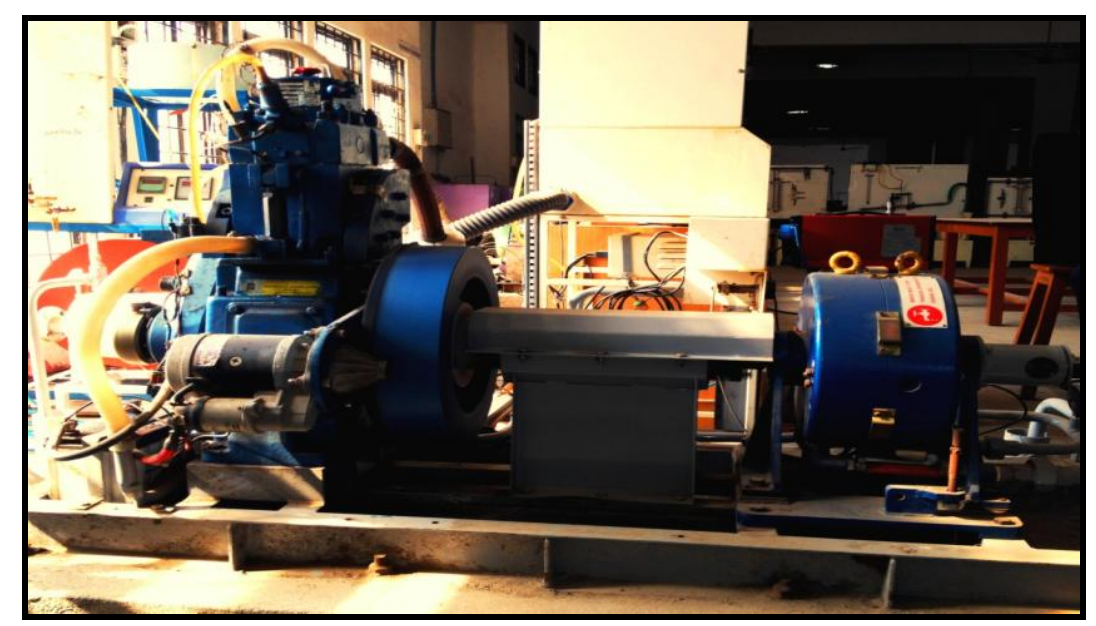

Fig. 1 Engine Testing Kit

Table-2.Technical Specification

\begin{tabular}{|l|l|}
\hline Model & TV1 \\
\hline Make & Kirlosker Oil Engines \\
\hline Type & Four stroke, Water cooled, Diesel \\
\hline No. Of Cylinder & One \\
\hline Bore & $87.5 \mathrm{~mm}$ \\
\hline Stroke & $110 \mathrm{~mm}$ \\
\hline Combustion Principle & Compression ignition \\
\hline Cubic Capacity & 0.661 liters \\
\hline Compression Ratio & $17.5: 1$ \\
\hline
\end{tabular}

IV. METHODOLOGY FOR OPTIMIZATION

Bi-fueling or blending is the simplest technique for admitting mixture of alternate fuel and diesel engines. In this method, the fuel selected for investigation is mixed with standard diesel oil in various proportions on volume basis and its properties such as calorific value was evaluated before admission. The blends with 10\%, 20\%, 30\% palm seed oil with standard diesel fuel. A method called 'Taguchi' was used in the experiment for simultaneous optimisation of engine such as compression ratio, injection pressure and load condition. 


\subsection{Taguchi Method of Optimisation}

Taguchi method is a simplest method of optimising experimental parameters in less number of trials. The number of parameters involved in the experiment determines the number of trials required for the experiment. More number of parameters led to more number of trials and consumes more time to complete the experiment. Hence, this was tried in the experiment to optimise the levels of the parameter involved in the experiment. This method uses an orthogonal array to study the entire parameter space with only a small number of experiments .To select an appropriate orthogonal array for the experiments, the total degrees of freedom need to be computed. The degrees of freedom are defined as the number of comparisons between design parameters that need to be made. The present study uses three factors at three levels and hence, an L9 orthogonal array was used for the construction of experimental layout (Table 3, column -1,2,3). The L9 has the parameters such as compression ratio, injection pressure and load arranged in column 1,2 and 3. (Table -4).

According to this layout, nine (09) experiments were designed and trials were selected at random, to avoid systematic error creeping into the experimental procedure. For each trial the mechanical efficiency was calculated and used as a response parameter.

Taguchi method uses a parameter called signal to noise ratio $(\mathrm{S} / \mathrm{N})$ for measuring the quality characteristics. There are three kinds of signal to noise ratios are in practice. Of which, the higher-the-better $\mathrm{S} / \mathrm{N}$ ratio was used in this experiment because this optimisation is based on brake thermal efficiency. The taguchi method used in the investigation was designed by statistical software called 'Minitab 16' to simplify the taguchi procedure and results. A confirmation experiment for the optimum set of parameters was also conducted for validation of the predicated value obtained by minitab software. This is mainly to compare the mechanical efficiency of predicated value and experimental value of optimum set of parameters.

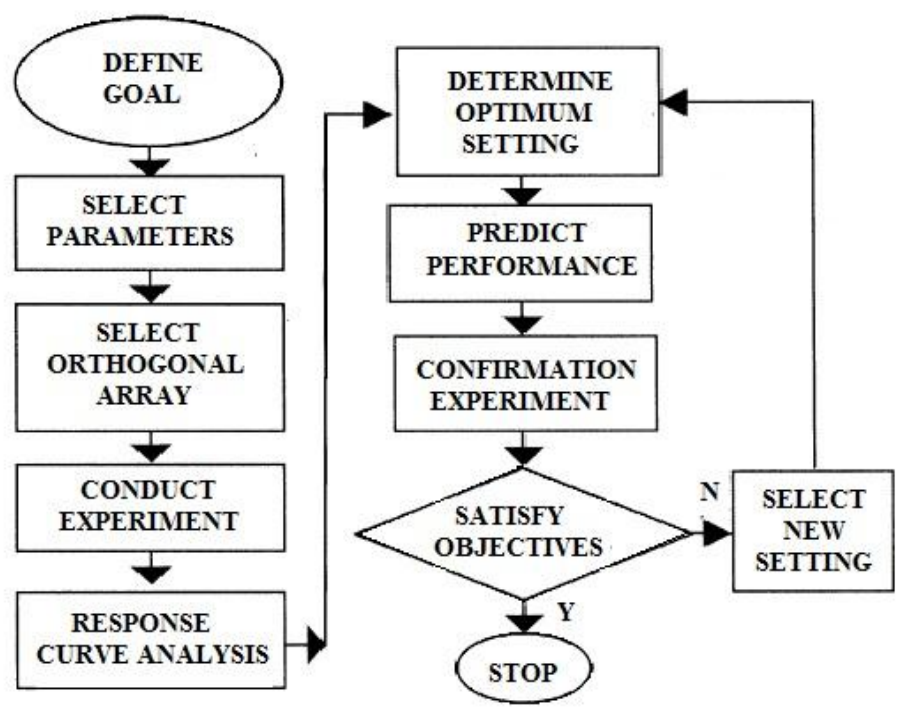

Fig.2 Flow chart of the Taguchi method

Experiment was conducted as per above step shown in flow chart of taguchi method.

\subsection{Selection of factor levels and orthogonal array}

In this experiment, three parameters for three levels were considered(table-3). Control parameter and their level are given in table. $L_{9}$ single orthogonal array shown in table-4(column-1,2 \& 3) was selected for the experimental investigation. "Bigger-the-better" is being taken as quality characteristics, since the objective function is to maximize performance.

Table-3 Process parameters and their level

\begin{tabular}{|c|c|c|c|}
\hline Parameters & $\begin{array}{c}\text { Compression } \\
\text { ratio }\end{array}$ & $\begin{array}{c}\text { Injection } \\
\text { pressure (bar) }\end{array}$ & Engine load (kg) \\
\hline Level 1 & 16 & 160 & 2 \\
\hline Level 2 & 17 & 180 & 6 \\
\hline Level 3 & 18 & 200 & 10 \\
\hline
\end{tabular}




\section{RESULT AND DISCUSSION}

Experiment was done for selected sets of parameters by Minitab software and find brake thermal efficiency for those sets of parameters. Brake thermal efficiency for those sets are given in the table.

Table- 4:-Result table for Brake thermal efficiency

\begin{tabular}{|c|c|c|c|c|}
\hline $\begin{array}{c}\text { Sr. } \\
\text { No. }\end{array}$ & $\begin{array}{c}\text { Compression } \\
\text { ratio }\end{array}$ & $\begin{array}{c}\text { Injection } \\
\text { pressure }\end{array}$ & load & Bte (\%) \\
\hline 1 & 18 & 160 & 2 & 13.14 \\
\hline 2 & 18 & 180 & 6 & 34.95 \\
\hline 3 & 18 & 200 & 10 & 32.46 \\
\hline 4 & 17 & 160 & 6 & 34.08 \\
\hline 5 & 17 & 180 & 10 & 41.92 \\
\hline 6 & 17 & 200 & 2 & 14.13 \\
\hline 7 & 16 & 160 & 10 & 36.42 \\
\hline 8 & 16 & 180 & 6 & 19.06 \\
\hline 9 & 16 & 200 & 2 & 30.65 \\
\hline
\end{tabular}

\section{ANALYSIS FOR RESPONSE CURVE}

Response curve analysis is aimed at determining influential parameters and their optimum levels. It is graphical representations of change in performance characteristics with the variation in process parameter. The curve gives a pictorial view of variation of each factor and describe what the effect on the system performance would be when a parameter shifts from one level to another. Fig:-4 shows significant effects for each factor for three levels. The S/N ratio for the performance curve were calculated at each factor level and average effects were determined by taking the total of each factor level and dividing by the number of data points in the total. The greater difference between levels, the parametric level having the highest $\mathrm{S} / \mathrm{N}$ ratio corresponds to the parameters setting indicates highest performance.

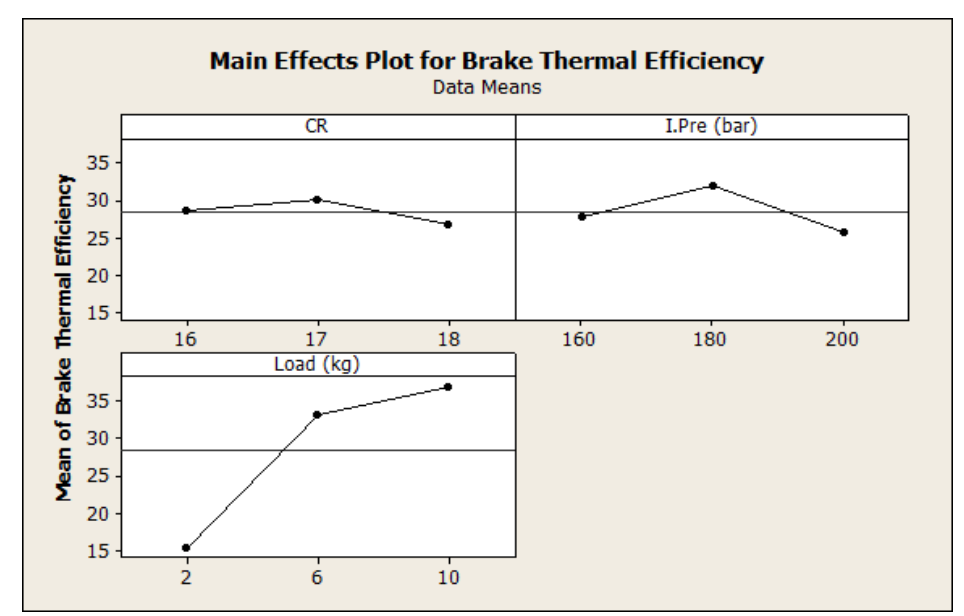

Fig.3 Main Effects Plot for Means of Brake Thermal Efficiency

From above Figure-3, the mean is an average value for reading taken for a particular parameter. From the graph, the mean value is the maximum (30.04) for 17 Compression Ratio \& minimum (26.69) for 18 Compression Ratio. The mean value is the maximum (31.82) for 180 bar injection pressure and minimum (25.74) for 200 bar injection pressure. The mean value is the maximum (36.93) for $10 \mathrm{~kg}$ engine load and minimum (15.44) for $4 \mathrm{~kg}$ engine load.

Delta is difference of maximum value and minimum value. Delta value is maximum for load parameter (21.49) and minimum (3.35) for the compression ratio parameter. The Delta value of Injection Pressure is between other two parameters and it is (6.08). So that effect of load is a maximum and effect of compression ratio is minimum on Brake Thermal Efficiency. 


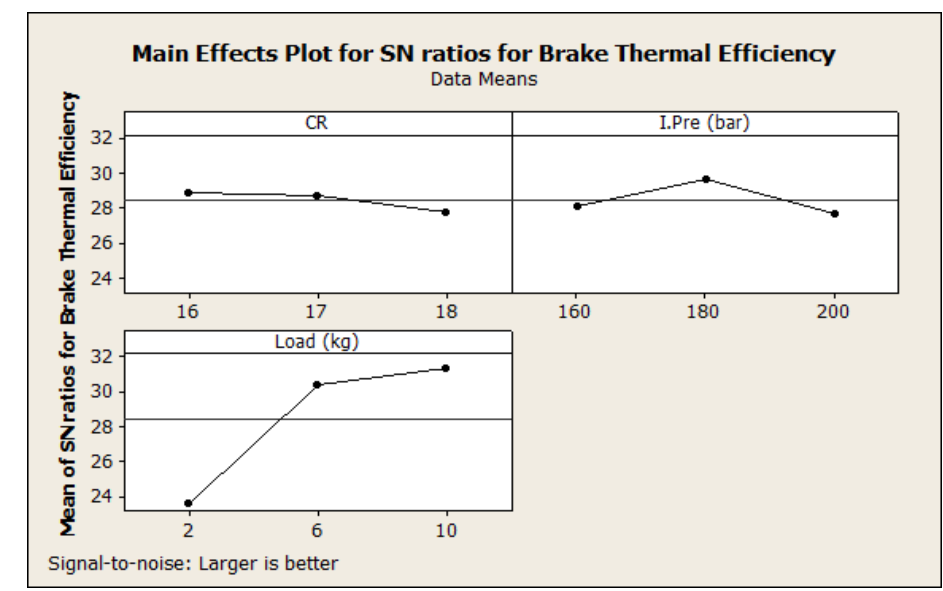

Fig.4 Main Effects Plot for SN ratios of Brake Thermal Efficiency

Referring (Fig:-4), the response curve for $\mathrm{S} / \mathrm{N}$ ratio, the highest $\mathrm{S} / \mathrm{N}$ ratio was observed at 16 compression ratio (28.85), engine load 10kg (31.10) and injection pressure180 bar (29.60), which are optimum parameter setting for highest brake thermal efficiency. From delta values as mention above, maximum of engine load is 7.64 and the minimum for compression ratio is 1.07 . The parameter engine load is the most significant parameter and blend ratio is less significant for brake thermal efficiency.

\section{OPTIMUM SET OF PARAMETER}

The term optimum set of parameters reflects only optimal combination of the parameters defined by this experiment for highest brake thermal efficiency. The optimum setting is determined by choosing the level with the highest S/N ratio. Referring Fig:-4 and Table-3, the response curve for S/N ratio, the highest performance at set 16 compression ratio, engine load $10 \mathrm{~kg}$, and injection pressure $180 \mathrm{bar}$, which is optimum parameter setting for highest brake thermal efficiency.

Table-5 Response table for signal to noise ratio

\begin{tabular}{|c|c|c|c|}
\hline Level & $\begin{array}{c}\text { Compression } \\
\text { ratio }\end{array}$ & $\begin{array}{c}\text { Injection pressure } \\
\text { (bar) }\end{array}$ & Engine load (kg) \\
\hline 1 & 28.85 & 28.08 & 23.66 \\
\hline 2 & 28.70 & 29.60 & 30.38 \\
\hline 3 & 27.78 & 27.65 & 31.30 \\
\hline Delta & 1.07 & 1.95 & 7.64 \\
\hline Rank & 3 & 2 & 1 \\
\hline
\end{tabular}

Using an optimum set of parameters, which was achieved by response curve analysis was used for prediction by Minitab software. Minitab software for Taguchi method of optimization was suggested maximum brake thermal efficiency $34.85 \%$ and $\mathrm{S} / \mathrm{N}$ ratio was 30.8953 for optimum set of parameter as shown in Table 6 .

Table-6 Predicted Values for Brake Thermal Efficiency

\begin{tabular}{|c|c|}
\hline Brake Thermal Efficiency & S/N Ratio \\
\hline 41.92 & 32.8634 \\
\hline
\end{tabular}

\section{EXPERIMENT FOR CONFIRMATION}

In this step of the process was to run confirmation experiments to verify the engine parameter setting really produce optimum performance and to evaluate the predictive capability of the Taguchi method for diesel engine performance. The optimum parameters were settled in the diesel engine and performance was measured for that set of parameter. As shown in table-5, This performance was compared with predicates performance and was found that the experimental value was nearer to the predicted value. 
Table-7 Comparison between predicated value and experimental value

\begin{tabular}{|c|c|}
\hline \multicolumn{2}{|c|}{ Brake Thermal Efficiency } \\
\hline Predicted Value & Experimental Value \\
\hline 41.92 & 40.80 \\
\hline
\end{tabular}

\section{CONCLUSION}

The Taguchi method was found to be an efficient technique for quantifying the effect of control parameters. The highest performance at set 16 compression ratio, engine load 10kg, and injection pressure 180 bar, which are optimum parameter setting for highest brake thermal efficiency. Engine performance is mostly influenced by engine load and is least influenced by bland ratio. Performance results obtained from the confirmation experiment using an optimum combination showed excellent agreement with the predicted result.

\section{REFERENCES}

[1] K. Sivaramakrishnan \& P. Ravikumar, "Performance optimization of karanja biodiesel engine using taguchi approach and multiple regressions" ARPN Journal of Engineering and Applied Sciences, April2012, Vol.7.No.4,PP. 506-516.

[2] Anant Bhaskar Garg, Parag Diwan, Mukesh Saxena, "Artificial Neural Networks based Methodologies for Optimization of Engine Operations"' International Journal of Scientific \& Engineering Research, May-2012, Vol.3 No.5,

[3] GVNSR Ratnakara Rao ${ }^{1}$, V. Ramachandra Raju ${ }^{2}$ and M. Muralidhara Rao ${ }^{3}$, "OPTIMISING THE COMPRESSION RATIO OF DIESEL FUELLED C.I ENGINE', ARPN Journal of Engineering and Applied Sciences, April-2008, Vol.3,No.2

[4] M.Natarajan, V P Arunachalam, N Dhandapani, "Optimizing diesel engine parameters for low emissions using Taguchi method: Variaton Risk Analysis Approach part-1', International Journal of Engineering and MS, June-2005,Vol.12,PP.169-181.

[5] N. Balajiganesh \& B. Chandra Mohan Reddy, "Optimization of C.I Engine Parameters Using Artificial Neural"' International Journal of Mechanical and Industrial Engineering (IJMIE),2011, Vol.1.No.2,

[6] Mr. Krunal B Patel1, Prof. Tushar M Patel2, Mr. Saumil C Patel3, "Parametric Optimization of Single Cylinder Diesel Engine for Pyrolysis Oil and Diesel Blend for Specific Fuel Consumption Using Taguchi Method" IOSR Journal of Mechanical and Civil Engineering (IOSR-JMCE),Mar-April-2013, Vol.6.No.1,PP 83-88. 